0 "4/SOURA UNIVE

aibl a

جامعة المنصـورة الماتع

كليـة الآداب

\title{
المسنات البديعية في شعر الشاب الظريف
}

\author{
إعـــ/د \\ سمر يوسف رياض أبو النجا \\ باحثه لارجة الدكتوراه بقسم اللغة العربية \\ كلية الآداب - جامعة المنصورة \\ إشراف \\ أ.د. أحمد حسين عبد الحليم سعفان \\ أستاذ الأدب العربي - قسم اللغة العربية \\ كلية الآداب -جامعة المنصورة \\ مجـلة كلــية الآداب - جـامعــة المنصـورة






\section{المهسنات البديهية في شعر الشاب الظريف}

\section{سمر يوسف رياض أبو النجا}




الموسيقيى الداخلية.





\section{Abstract:}



The music in the poetic text doesn't depend on the rhyme or the external music only, but also it depends on the internal music which is considered as an impressive sort of music in poetry. It helps in building the poem and the poetic experience, and it is emitted from the harmony of vocabulary. Moreover, it depends on the rhythm and the figure of speech which hare a great musical effect.

This research cleals with the musical aspects and some fields of rhetoric in Al-Shab Al-zareef's poetry. These musical aspects are alliteration, homeoptoton, leonine rhyme, isocolon and word spread.

ونلحظ أن الموسيقى الداخلية في شعر


الجرس الموسيقي الموثر، والتي تحدث عندما" تتعانق الأصوات متلائمة ، متوافقة، منسجمة في ولجي لحني




على القصيدة وقعا معينا، قوة وسموًا ، أولينا



وبهذا فإن " شأن موسيقى الإطار تحتضن

موسيقى الحشو في الشعر، شأن النغمة الواحدة


الغناء "(i). (2)

وتتمثل مظاهر الإيقاع عند الثاب

الظريف في بعض مباحث علم البديع، والتي رَّن بها الثاعر قصائده ، واعتمد عليها في إضاءة نصوصه الشعريه، وهذه الألوان البديعية هي :


ولزوم ما لا يلزم.



ويعد شاعرنا من شعراء العصر المملوكي

الذين اهتموا بصنعة البديع، حيث نلحظ عند الثاب الظريف حسن وروعة توظيف لهذه الأساليب البديعية.

وحد الموسيقى الداخلية أنها" ذلك الإيقاع

الهامس الذي يصدر عن الكلمة الواحدة، بما تحمل في تأليفها من صدى ووقع حسن، وبما لها لها من رهافه ودقة تأليف، وانسجام حروف ، وبعد عن التنافر وتقارب المخارج" (1). أهـا الإيقاع فهو" ما يحدثه الوزن أو اللحن من



ولا شك أن الإيقاع مرتبط بالوزن ارتباطا


الإيقاع ليس هو الوزن نفسه.

وكأن الإيقاع هو روح القصيدة والونن جسدها، ذلك أن الإيقاع غير منظور ولكن روح الإع المستمع يحس به عند سماعه للوزن الثعري. 
أنواع: ا- نوع الحروف، ب- عدد الحروف، س-

هيئة الحروف، ع - ترتيب الحروف"(؟). وبهذا فقد قسم الجناس إلى نوعين: " تام،

غير التام، فالتام هو ما اتفق فيه اللفظان في أمور أربعة هي: نوع الحروف، وشكلها، وعددها وترتيبها. وغير التام: وهو ما اختلف فيه اللفظان

في واحد من الأمور الأربعة المتقدمة " (Y). وعلى ذلك فإن الجناس التام ينقسم قسمين" منه أن يتفقا في أنواع الحروف وأعدادها وهيآتها وترتيبها، فإن كانا من نوع واحد كاسمين





\section{(أ) جناس تام متماثل:}

وكما ذكرنا آنفا أن هذا النوع من الجناس

يكون بكلمتين متجانستين من نوع واحد : اسمين



\section{ودع الهموم إذا هممت بوصلها}

عذراء من يد غَادةٍ عذَّراء



كلمتي(عذراء) الأولى، وهي بمعنى الخمر التي لم تمس، وكلمة ( عذراء) الثانية وهي الحسناء البكر، وقد أضفى هذا الجناس على مضمون البيت قوة في التعبير والإيقاع.

ويقول في شاهد آخر من بحر الكامل: (·)

لكنتي أُهوى وفَاكَ وفَكَ إذْ


أبدع الثاب الظريف في هذا اللون الموسيقي عندما جانس بين ( وفالك) وهو عهد المحبوبة ووفاؤها الذي يهواه رغبة بمنزلة رفيعة،
لا يخفى على متذوقي الشعر ما للجناس من تأثير ظاهر وجرس رنان يضفي رونقا وهالة من الجمال على القصيدة ، والجناس من أكثر فنون البديع الإيقاعي التي حظيت باهتمام كبير من النقاد والبلاغيين العرب القدماء ، ولعلَّ ذلك لك بلكي يعود إلى كثرة الأنواع التي تتدرج بداخله ، وأيضا كثرة الشواهد الشعرية التي ملأت دواوين الشعراء من هذا النوع البديعي. والجناس لون من ألوان الجمال اللفظي ومصدر للتلوين الموسيقي ينشط الذهن ويسهم في إيضاح المعنى ويحسن " إذا قلَّ وأتى في الكلام عفوا من غير كد ولا استكراه" (0). وقد ألفينا للجناس حضورا جميلاً لدى الثاب الظريف؛ لأهميته في البناء الفني لموسيقى الثعر عنده، ولاهتمامه بالجانب الصوتي، فثاعرنا في الجناس يستغل القوة التعبيرية في جرس الألفاظ لتوليد المعنى الذي تهيئه اللغة في اشتقاقاتها.

وقد ذكر البلاغيون أنواعا كثيرة للجناس، كل نوع منها أخذ مسمى تبعا لنوعية الجناس بين الكلمات، ومن أنواع الجناس التي وردت في ديوان الثاب الظريف: الجناس التام- الجناس الناقص - جناس الاشتقاق - الجناس المحرف- الجناس اللفظي- جناس التصحيف- جناس التصريف . 1- الجناس التام:

ويقصد به الجناس الذي" اتتق ركناه لفظا واختلفا معنى بلا تفاوت في تركيبهما ولا اختلاف في حركاتهما. والاتفاق اللفظي يشمل أربعة 
ومن أمثلته عند الثاب الظريف، قوله من بحر الكامل: (10)

$$
\text { أَنْكرتُ صبرا عن عهودي نَكَّبا }
$$



أوجد الجناس إيقاعا صوتيا مطرَبا بين

كل من ( عرفت) الأولى وهي فعل و(عرفهم) الثانية وهي اسم بمعنى الرائحة الطيبة.

ويقول من بحر الكامل:(1)





ففيه جناس مستوفي ؛ لأنه بين الفعل

(جار ) بمعنى ظلم والاسم ( جار ) أي من يقاسمه لانه بن ويشاركه في قلبه.

وفي مثال آخر من بحر الطويل:(IV)





والجناس هنا في كلمة ( الخل) وهي اسم

و(خل) الثانية وهي فعل، والمعنى أنه يدعو وهي






عقل المتلقي. r- ب - الجناس الناقص:

وهو " الذي يوجد في إحدى كلمتيه حرف لا يوجد في الأخرى وجميع حروف الأخرى يوجد



وسمي هذا النوع من الجناس ناقصا؛ " لأن اختلاف الركنين في عدد الحروف يلزم منه



وبين ( وفالك) الثانية وهو فم المحبوبة الذي يحبه الثاعر طمعا بارتشاف شهده. ويقول مادحا من بحر المنسرح: (')



\section{مذْ عدمت عينِي له مثَلا}

في هذا البيت جناس تام متماتل بين

كلمتي ( مثلا) في الثطر الأول وهي بمعنى الثبيه والنظير، وكلمة ( مثلا) في الثطر الثاني

وهي القول المأثور، وبهذا الجناس أحدث الثاعر تناغما صوتيا يؤثر في نفس المتلقي .


قد خبَّت الخَاتم بالخَاتم خَبَّتهَه في فيها فَقُلْتَ انْظُروا

وهذا البيت من بديع ماورد عند شاعرنا


الزينة الذي يوضع في إصبع المحبوبة، (وخاتر الثانية) قصد به فم محبوبته، وهذا الجناس يولد إيقاعا صوتيا مطربا.

وبهذا فإن " جماليات هذا الفن تقوم على

وحدة الإيقاع مع تباعد المعنى، وفي هذا مخاتلة للمتلقي تفضي إلى إعمال عقله وتحقيق علاقة إيجابية بينه وبين المبدع"(r'). (ب) (جناس تام مستوفي:


حيث تتجانس فيه كلمتين ولكن من نوعين كاسم وفعل، وقد سمي هذا النوع من الجناس (مستوفي)


ينتقص شيء من حق الجناس"(؛) '). 




وهو" مـا يقـع التخـالف فيـهـ بـين الضـاد







شاعرنا في بيتين، يقول في أحدهما من مجزوء الوافر :(ro).

لقَّ أصميتَ بالنظظره

رشيق القامة النَّره

(T): أمَّا الآخر فيقول فيه من بحر الرجز

\section{وهذه نواظر ذوابل}

فَهذه ذَوابل نَواضر

ففي كلا البيتين جانس الثاعر بين كلمتي


من ( نواضر) و( نواظر) ، وقد وقع التخالف بينهما في حرف الضاد والظاء. ع - الجناس المحرف:

ويطلق عليه أيضا جناس التحريف وحدُه"

مـا اتفق ركناه في عدد الحروف وترتيبها واختلفا في الحركات"(YV)، بمعنى أن " يكون الثكل فارقا بين الكلمتين أو بعضهما"(N)


أنه إن اختلف الجناس " في هيآت الحروف فقط سمي محرفا"("r9). وقـد ســي بــلك؛؛" لانحــراف هيئـة أحـــ


التحريف، والجناس الدغاير والدختلف"(·).
ومن أمثلة الجناس الناقص عند الثاب الظريف قوله متغنيا بمباهج الربيع من بحر الكامل:(•r). في راحة السَّاقي قَيص هواء جانس الثاعر بين كلمتي(راح) و(راحة) وقصد بالأولى الخمر أمَّا الثانية فقصد بها كف الفي اليد.

(r): وقال في مثال آخر أيضا من بحر الكامل إثْر الخَلَيط فجرحهنَّ جبارِ ودم ودمع حين يختلطان في

وقد رسم الجناس بين(دم) و( دمع) صورة امتزاجها إثر رحيل الأحبة ، حتى صار جرحهن مهلك مؤلم.

وجاء الجناس معبرا عن المعاناة التي تعيشها المحبوبة حين أذن داعي السفر بيوم الوداع ، ونلمس ذلك في الجناس بين ( وداعي)


الكامل: (r)


خَافَتْ من الرُوََبَاء يوم ودَاعي

ويتضح الجناس الناقص بين كل من




والجفن قريح ، وحرقة الثوق دائمة ، وذلك في


والجفن دام والجوى دائم

الأَّمع هام وإلحثا هائم

وبهـا الجنـاس القـائم في شطري البيت أحدث الثاعر تتاغما صوتيا في الإيقاع • 
نلحظ أن " تغير حركات بنية الكلمة يؤدي إلى تتوع في الإيقاع ويجعله جامعا بين الوحدة

$$
\text { والتتوع"(ro( ). }
$$

$$
\text { ه-جناس التصريف: }
$$

ويقصد به" اختلاف صيغة الكلمتين

بإبدال حرف من حرف، إمَّا من مخرجه أو من

$$
\text { قريب منه"(Tr). }
$$

ويفهم من هذا أنه لابدَّ وأن يقع الاختلاف في رئه

$$
\text { حرف واحد لا أكثر. }
$$

ومن أمثلة ما أورده الثاب الظريف في



لنَاظريَّ سهادي في الأجى وهبوا

إنَّ الذين فُؤادي في الهوى نهبوا



(وهبوا) ، وكلاهما اختلفا في الحرف الأول ،

وبهذا أضفى الثاب الظريف على مضمون البيت

$$
\text { قوة في التعبير والإيقاع. }
$$



فَخَلَعت فيكَ عذَار علْمي أَثْيبا





تصريف ، وقدأبدل الثاعر حرف الميم بحرف

النون ليذهب إلى مقصده من أنَّ هوى محبوبه

أزال منه تمسكه بالزهد والعبادة.

وقوله متغزلا من بحر البسيط(ra)
ومن شواهده لهذا النوع من الجناس قوله

مادحا رسول الله صلى الله عليه وسلم من بحر البسيط:(')







وفتحها جناس تحريف، هذا الجناس وئه إيقاعا صوتيا نتيجة اتحاد اللفظين في الثكل واختلافهما في حركة الحرف الثالث منهما. وكذلك قوله من بحر البسيط:(rr) وكم شكوت فلم تصغوا إلى حجبي

مرَّت على طول المدى حجبي

جناس التحريف واضح بين كلمة(حجبي) الأولى وقصد بها الثاعر السَّنة و(حجبي) الثانية وقصد بها البرهان والدليل، وهذا التماتل في الحروف مع اختلاف الحركات يلفت انتباه



وقال من مجزوء الرجز : (rr) فيهه كَلَونْ شَعْرِ

غَرَا وحَظ شعْره

بين(شعرِ) و(شعره) جناس تحريف، وهذا الجناس يمنح البنية الداخلية للقصيدة جرسا جناس تحرنا موسيقيا متتاغما.





فُقال لي تَبغي وصِال الرَّشَّا

وجناس التحريف واضح بين عروض ليفي

البيت وضربه، حيث تعاتب المحبوبة شاعرنا

بقولها : تريد وصال الغزال ولا تدفع الثمن ، وبهذا 
بين كلمتي (خطبا) ، (حطبا) ، وقد اتفتا في

داني المزار وأبكِي كُلَّ مغترب



وجناس التصريف يتضح بين (مقترب)، ويقول من بحر الطويل:(1)؛.



وكنز اصطباري عند فَقْلك نافْ

الحرف الثاني.

وقد اتضـح الجناس من خلال التقارب الصوتي

ويقول من بحر الطويل:(•).

لحروف الكلمتين( نافد)، (نافذ).

ويقول من بحر الوافر (\&). وكنَّ على العثَّاق شِرِّ سوالب

جلون على الأَحداق خير سوالفٍ

وبعض هواكم كلي يحوز

سلوي عن هواكم لا يجوز

وجناس التصحيف بين( يجوز) و( يحوز)

ة




البيت الشعري.

فبين (سوالف)، (سوالب) جناس تصريف أبدل فيه الثاعر حرفٍ الفاء بالّاء؛ ليذهب إلى مقصده من نسوة كثفن لعيون ترنو لهن عن سوالف وضاحة ، وكنَّ لعشاقهن مصايد يسلبن قلوبهم وعقولهم. צ-جناس التصحيف:

ويقول في موضع آخر جامعا في قلبه منزلة المحبوب ومعناه من خلال جناس التصحيف بين(مغناكم( و( معناكم)، يقول من بحر السريع(^). في القلب مغناكم ومعناكم يا من خلا من حسنهم ناظري



وهو من اسمه الجناس الذي" جمع ركنيه

أصل واحد في اللغة، ثم اختلفا في حركاتهما وسكناتهما"(9 §).

ويسمى أيضا" الجناس المشتق، وجناس الاقتضاب، وهو ما توافق فيه اللفظان في الحروف الأصلية مع الترتيب والاتفاق في أصل المعنى" (0.) (1) هذا نوع من الجناس " منهح من يسميه جناس الخط، وهو ما تماثل ركناه خطا واختلفا لفظا( من جهة النقط)"(اء) ، بحيث" لو أزال إعجام


حروف" القاف والفاء والباء و الياء و النون والتاء والعين والغين "(rاء). وسمي جناس التصحيف بهذا الاسم؛" لأن من لا يفهم المعنى، فإنه يصحف أحدهما إلى الآخر ؛ لأجل تثابهما في الخط"(؛ ؛). ومثاله قول شاعرنا من بحر البسيط:(؛)؛




يوصي شاعرنا محبوبه وقد ابتغى وصله وطلب رضاه ، أن يشعل فيه نارا وقودها من أحشائه ، معتمدا في هذا المعنى على الجناس وذلك في مثل قوله من بحر الكامل(10) 




يبرز التصريع بين ألوان البديع بوصفه من أهم الأدوات الفنية المحققة للموسيقى الداخلية، فهو يسهم في إثراء الحركة الموسيقية اللازمة لبناء القصيدة الفنية لما فيه من تتاغم يجعل النفس تتلقاه بالارتياح والقبول.

والتصريع في أبسط التعريفات " استواء آخر جزء في صدر البيت وآخر جزء في عجزه في الونن والروي والإعراب، وهو أليق ما يكون


والأسماع "(00). وقيل في الثرق بين مجيء التصريع عند كل من القدماء والمحدثين أنه " كثير ما يأتي في أثناء قصائد القدماء ، ويندر مجيئه في أثناء قصائد المحدثين، ووقوعه في الأشعار دليل على غزر مادة الثعر، وحكمه في الكثرة والقلة حكم بقية أنواع البديع إذ كلّ ضرب منالبديع متى كثر في شعر سمج، كما لا يحسن خلو الكلام منـه غالبا ، وكل ما جاء منه متوسطا من غير تكلف فهو المستحسن "(40). ويعد التصريع من أمارات إجادة الثاعر وتعلقه بفنه فهو يهيء أذن المتلقي ويمهد لمعرفة القافية، وهذا من شأنه أن يعمق النغم الداخلي في البيت بتوافقه مع مضمون النص الثعري. وقد أورد ابن الأثير فائدة التصريع في الشعر بقوله" إنه قبل كمال البيت الأول من القصيدة تعلم قافيتها ، وشبه البيت المصرَّع بباب له مصرعان متشاكلان، وقد فعل ذلك القدماء
لا بـ آّ مثل مبيت مهجته



المكان(مبيت)، وكلها تدل على رجاء الثاعر ألغ يبيت محبوبه وروحه موطنا للهموم ومجمعا



ويقول في موضع آخر يمدح فيه أحد القضاة من بحر البسيط(or).





جانس الشاعر بين ثلاث كلمات بين

الفعل (ضربت)، والمصدر (ضرب)، واسم المفعول(مضروب)، وهذا الجناس يحدث نفس التتاغم الموسيقي الصوتي المؤثر في المتلقي. ومن نفس القصيدة، يقول من بحر البسيط:(مr). ولا يثق صماحب فيه بدصحوب

فَلا يرق مسكن فيه رسماكنه

وجناس الاشتقاق واضح بين كل هن

(مسكن)، (ساكن) وكذلك ( صاحب) ،(مصحوب) وهذه الكلمات كلها مشتقة من أصل لغوي واحد.






فجناس الاشتقاق بين (ترتاع)، (ارتياع)، (مرتعا) وكلها مشتقة من أصل لغوي واحد، بحيث يحدث نوعا من الإيقاع في بنية البيت. 
بتَثَّي قَوَامك الممشوق

وبأَنْوارِ وجهِكَ المعثوق



توافق ضـربها في حركاتـه وسكناته، وتماثلـة في

الصيغة الاشتقاقية التي جاءت عليها وهنا يكمن

أثر التصريع.

ويقول من بحر الوافر (rآ).



أَعرَّ الله أنصار العيون

نرى حالة التتاغم الموسيقي بين شطري

البيت. كأنما هناك قافية داخلية إلى جانب قافية

البيت الأصلية، وقد صنع التصريع هذا التتاغم . ومنه أيضا قوله من بحر الكامل(rآج).



ماست فَقَيل هي القَضِيب الأَميدِ

هذا البيت مطلع لقصيدة غزلية، جعل

فيها الثاعر التصريع تهيئة للتعرف على القافية، وكذلك نغما غاية في الجمال.

وقد يجمع الثاعر بين التصريع والتجنيس

في مفتتح قصائده، مدرّلا بذلك على حسن اختياره


التصريع والجناس يثير إلى عمق التأثير

$$
\text { الإيقاعي لكل منهما في بناء القصيدة. }
$$

ومن أمثلته للقصائد التي جمع فيها بين

التصريع والتجنيس قوله من بحر الكامل:(ء) ولصبه المضنى إليه تذلّل



$$
\text { ومنها قوله من بحر الواَفر:(70) }
$$

والمحدثن، وفيه دلالة على سعة القدة في أفانين

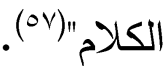

وقد جعل ابن رشيق" اشتقاق التصريع من

مصراعي الباب، ولذلك قيل لنصف البيت (مصراع)، كأنه باب القصيدة ومدخلها، وقيل: بل هو من الصرعين، وهما طرفا النهار"((ه). وأغلب القصائد عند الثاب الظريف مطلعها مصرَّع، ولا غرو في ذلك فقد كان الشعراء يهتمون بافتتاح قصائدهم ويتبارون في الأفضلية، وذلك لأن قوة تأثير التصريع بمقدمة القصائد تترك بك أثرا موسيقيا كبيرا في أذن المتلقي منذ الوهلة الأولى لسماع القصيدة أو قراءتها. ومن أمثلة وشواهد هذا النوع من المحسن البديعي قول شاعرنا مادحا قاضي القضاة من بحر المنسرح) (ب9) أَضْحى لَّهُ فَي اكَّْئَابه سبب جعل الثـاعر عروضــه وضـربه متوافقان متمــاثلان ليرســـم لنـــا نغدـــا موســيقيا مـــن خلال التصريع. وفي مثال آخر مـا قالـه في قصيدة مطلعها من بحر البسيط(، (7) وللأحبَّة إنَ لَم يألْفَوا الصَّلَفا



إذ يهيء التصريع أنغاما موسيقية داخلية غاية في



وقوله مصرعا مطلع قصيدته من بحر الخيف(1) 
لا يقبل على هذا الفن إلها الحاذق المتمكن من



ومن أمثلة الثاب الظريف في هذا اللون،

$$
\text { قوله من بحر الوافر :(v) }
$$



عذابي من ثَناياك العذاب

$$
\text { طلاب للشَّراب منَ السَّراب }
$$

تكلف من تكثَف منك ودَّا

$$
\text { أَضْاف لَكَ الجمال إلىى الحجِاب }
$$

نسبت إلى الجمال وفيك بعد

كما زعم الوشاة ولا بعاب

أُما وهواي فِيك لغَير عار

\section{وما يحويـه خدُّك لاجتناءٍ}

وهنا ساهم وجود الألف 'المتتالية قَبل

حرف الروي بإطالة الصوت معززا الزمن الإيقاعي

لبحر الوافر، ثم إنَّ إثباع الثاعر لحركة ( الباء

المكسورة) منحه فرصة كبيرة في أن يمد الصوت

الإيقاعي لأبياته الشعرية ومن ثم استيعاب أكبر

قدر ممكن من انفعالاته وتجاربـه العاطفية .

ومن النماذج الرائعة التي استخدمها

الشاب الظريف في هذا اللون قوله من بحر

(vi) (الكامل:
وليس لايك للعشاق عدل

فَديتِك كم عليَّ عليكَ عَذْل

ويؤدي التصريع في كَل هذه الأمثلة دورا

في التأثير في نفس المتلقي فيجعله متشوقا للاستماع إلى باقي أبيات القصيدة ، ويزداد وقع أثز التصريع بتجنيس كلمتيه .

\section{ثالثًا : لزوم ما لا يلزم}

ويقصد به" أن يأتي الثاعر بحرف ملتزم



وحده عند الخطيب القزويني" أن يجيء

قبل حرف الروي وما في معناه من الفاصلة ما ليس بلازم في مذهب السجع"(TV).

وقد جعل ابن الأثير هذا اللون البديعي

في كتابه المثل السائر" من أشق هذه الصناعة الصئ مذهبا ، وأبعدها مسلكا؛ وذلك لأن مؤلفه يلتزم ما لا يلزمه.... وهو في الشعر أن تتساوى الحروف التي قبل روي الأبيات الثعرية"(^آ)؛ ولذلك " " يطلق هذا الاصطلاح على القيود التي يلتزمها بعض الشعراء من دون أن تكون الصناعة ملزمة لهم بذلك ، وأهم هذه القيود التطوعية أن يلتزم الشاعر قافيتين"(79).

ولعلَّ أيَّ شاعر يلجأ إلى هذا اللون

البديعي، يريد أن يظهر براعته ومهارته الفنية؛ لأنه يلزم نفسه حرفا معينا قبل الروي، وفي هذا الالزام شيء من التكلف والتَعنت، ولكن الثاعر ذو الحنكة اللغوية والمراس الأدبي يخرج لنا قصيدة من هذا النوع دون أن نشعر فيها بعناء النظم أو تكلف القافية، فضلا عما نحسه من دفقة شعورية تحمل صدق العاطفة والإحساس ؛ ولهذا 
وقد ورد الترصيع كثيرا في شعر الثاب

الظريف وزين به أبيات قصيده ومثاله قوله من

$$
\text { بحر الكامل:(V乏) }
$$

بالطرَّة السَّودْاءَ فَوَق الغُرَّة الـ

بيضاء فَوَق الوجنة الحمراء

والترصيع واضح في البيت بأكمله ويتكون فون الترة

من ثلاث رصائع أو جمل، وجماليات هذا النمط


المستوى الصوتي.

ومنه قوله من بحر البسيط:(vo)





والترصيع بين جملتي الثطر الأول

والثاني من البيت، فكلمة (كحل) بإزاء كلمة (خضب)، ( المقلة) بإزاء (الوجنة)، (السوداء)


(بالضرج) • ومن شواهد الترصيح أيضا قوله من لئن





$$
\text { عن طريق الترصيع. }
$$

ومن نفس القصيدة البيت الذي يليه

مباشرة، وفيه يقول:

سَفّاح أَو فَبْطَفْكَ الرَََّّّاح



ومن خلال توالي هذين البيتين من نفس

القصيدة يبرز لنا التصريع على المستوى الأفقي
واشرح هوإك فَكلنا عثَّاق

لا تُخفِ ما صنَعَتْ بكَ الأَثْواق

جاري ولَوَلَا قَلَبك الخَقَاقَ

قَّ كان يخفي الحبَّ لَولَا دمعك الـ الـ في حمله فَالعَاشقُقون رِفَاقِ



فَتكت به الوجنات والأَحداقِي.

لا تَجزَعنَّ فَلَستَ أَوْل مغُرم

عادَ الوصال ولْهُوي أُخْلاق

وإصبر عَلى هَرْ الحبيب فَرَبَّما

ألزم الثاعر نفسه في هذه الأبيات حرف

الألف قبل الروي( القاف)، ونرى مع هذا الإلزام


في حركاتها ، تتوالى معه القوافي خفيفة الوقع رشيقة البنية.

وبهذا استغل الثاب الظريف ما يمكن أن

يمنحه هذا الميدان لتجاربه الأدبية من جمال وقوة في الجرس الموسيقي؛ ليظهر فيه براعته ومهارته الفنية بين الثعراء.



وهو من الظواهز البديعية التي تبعث الموسيقى في البيت الثعري عن طريق التوانن وتقسيم البيت. والترصيع في أبسط تعريفاته" أن يكون


معتدلا مع التقفية. أمَّا لفظه " فمأخوذ من مقابلة ترصيع




وقسم على العكس، وهو الذي لا يشترط فيه

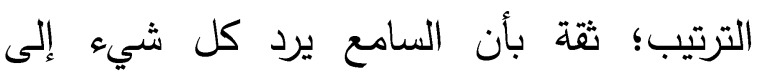
موضعهة، تقدم أو تأخر "(•).






بشكل بديهي يرد كل واحد منهما إلى ما يليق به.





\section{في ثَغْره ونَاظرِيَ}

وهو في هذا البيت جمع بين ثغره وناظريه

بواو العطف، ثم بعد ذلك أضاف إلى كل واحد منهما ما يليق به، فأضاف العذب إلى ثغره، وأضاف العضب إلى ناظريه واصفا ما في ثغر لئر محبوبه بالريق العذب وما في عينيه من نظرة

حادة قاطعة.

وكذلك قوله من بحر الكامل:(r)




وهنا طوى المعنى في الثطر الأول ثخ بسطه في الثطر الثاني ، وذلك عندما طلب من محبوبه أن ينزع النقاب عن فمه، وأن يلقي الرداء


وقامة غضة طرية كالصديا. (Ar): ومن شواهد اللف والنشرَ قوله من بحر الرجة الماء والخضرة واللوجه الحسن في جسمه وصدغه وشكَله وبهذا لفَّ الألفاظ وجمَعهم في الثطر ونَ الأول ، ثم نشرهم في الثطر الثاني.
في البيت الواحد، وكذلك المستوى الرأسي على




ويحلو بكم هزل العتابِ وجدُّه

يَلَّ بكم سرجل الغرامِ وصعبه

وهنا حاكي الإيقاع الموسيقي في البيت

الحالة النفسية للشاعر عن طريق الترصيع.


حمراء في عينه سوداء في كبده صفراء في وجهه خضراء في فَمه يمتد الترصيع في شطري البيت مكونَاً بنيته الإيقاعية، من خلال التوازي والتتاسب الذي يرسمه داخل البيت الشعري.


مجرد ثُوب سلواني ومخلقه

مجدد مطل ميعادي ومخلفه



والثطر الثاني، وذلك في توافق الجملتين وتوازيهما، وهذه القيمة الإيقاعية التي صاغها الترصيع تطرب لها الآذان عند سماعها.



وهو " أن تذكر شيئين فصاعدا، إمَّا تفصيلا فتتص على كل واحد منهما، وإما إجمالا فتأتي بلفظ واحد يشتمل على متعدد، وتفوض إلى فلى والى العقل رد كل واحد إلى ما يليق به... ثم إن المذكور على التفصيل قسمان: قسم يرجع على المذكور بعده على الترتيب من غير الأضداد؛


للثاني، وهذا هو الأكثر في اللف والنشر والأشهر، لالول 
وبهذا فإن الألوان البديعية التي وردت في


وزينت موسيقى أبيات قصائده، وأظهرت ما لثاعرنا من مقدرة لغوية داخل بنية قصائدة ومن

$$
\text { ذوق فطري يطرب القلوب والأسماع. }
$$

الهموامش







r- أحمد مطلوب : معجم مصطلحات النقد العربي القديم ، دار الثئون الثقافية العامة ، بغداد، الطبعة



r- عبد الرحمن الوجى : الإيقاع في الثعر العربي ،

.$V Y$

ع- حمد الهادي الطرابلسي : خصائص الأسلوب في

الثوقيات ، منشورات الجامعة التونسيه ، 1919 ام ،



0- مصطفى الصاوي الجويني : البلاغة العربية تأصيل





צ- علي الجندي : فن الجناس (بلاغة - أدب - نقد) ،



- V

والبيان والبديع ، توثيق: يوسف الصميلي ، المكتبة



1- الخطيب التزويني : التلخيص في علوم البلاغة ،

ضبط وشرح: عبد الرحمن البرقوقي ، دار الفكر



9- (الديوان : صلr



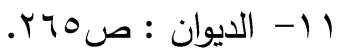

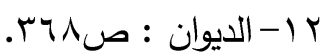



وعظيم مطلوبي عليك يسير

دمعي وقَلْبي مطلْقَ وأَسِير

ويتضح اللف والنشر في الشطر الأول

فقط بقوله دمعي حرٌ وقلبي سجين.

ومن نماذجه أيضا لهذا النمط قوله من



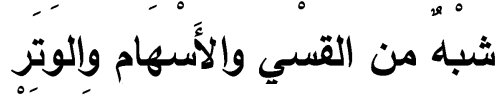

\section{في حاجبيه وعينيه ومنطقه}

يقول حاجباه مثل القسي، وعيناهَ تشبهان

السهام، وحديثه كأنغام الوتر .

(^): ويقِول متغزلا من بحر الرجز

من ريقه وخده وصدغه

\section{فخمره وورده وآسه}

يعتمد اللف والنشر على أن السامع يرد

كلإ إلى ما يناسبه بالفطرة ، فشاعرنا فاز بالخمر من ريقه، وبالورد من خده، وبالآس من جانب

وجها.

ولعلَّ من جميل نماذجه في هذا اللون





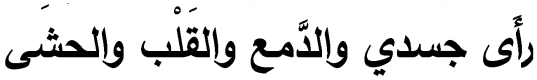

وقد قام التناغم الإيقاعي في هذا الفن

البديعي على طي الألفاظ ثم نشرها بما يلائم كل لفظة، بحيث تتجلى جماليات الإيقاع في اللف والنشر بتضافر الألفاظ بمعانيها كالطراز ينسج في الثوب بشكل إيقاعي منتظم يدعم ما في خاطر الثاعر، معتمدا في ذلك على الذوق الفطري للمتلقي في رد الثيء إلى ما يناسبه. 


$$
\text { ع ا- الديوان : ص9911. }
$$

هץ- سمير السعيد حسون : البديع الإيقاعي في شعر



צr-ابن أبي الإصبع : تحرير التحبير ، صلع •l.



$$
\begin{aligned}
& \text { مץ- الديوان : ص • ז. } \\
& \text { qץ- الديوان : صهץ. } \\
& \text { • ع- الديوان : ص^^ه. }
\end{aligned}
$$

اء- مصطفي الصاوي الجويني : البلاغة العربية تأصيل



r ب- السيد أحمد الهاشمي : جواهر البلاغة في المعاني

والبيان والبديع ، توثيق يوسف الصميلي، المكتبة











$$
\begin{aligned}
& \text { هـ-الديوان : ص1ه }
\end{aligned}
$$



$$
\begin{aligned}
& \text { V }
\end{aligned}
$$



9 9 البديع ، مطبعة الجوائب ، قسطنطينية ، الطبعة





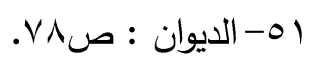







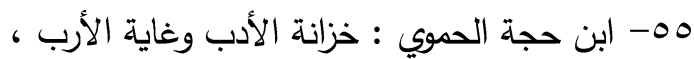





$$
\text { . } Y \vee \wedge / T
$$

rا-سمير السعيد حسون : البديع الإيقاعي في شعر

صريع الغواني ، مجلة كلية الآداب ، جامعة الإبعاعي فيل

المنصورة ، إصدار خاص ، يونيو · ( •بم ،

ص ص



10 - الديوان : صع T.





11 - ابن أبي الإصبع المصري : بديع القرآن ، تحقيق:







• r- الديوان : صلrr.







ع צ-جلال الدين السيوطي : جني الجناس ، تحقيق

ودراسة وشرح : محمد علي رزق الخفاجي ، الدار

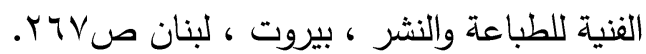

$$
\begin{aligned}
& \text { هץ- الديوان : صrז } 1 . \\
& \text { צr-الديوان : ص1هr. }
\end{aligned}
$$

rV - مصطفى الصاوي الجويني : البلاغة العربية تأصيل



^ץ- ابن أبي الإصبع المصري : تحرير التحبير في صناعة الشعر والنثر وبيان إعجاز القرآن ، تحقيق: حفني ححم شرف ، المجلس الأعلى للشئون



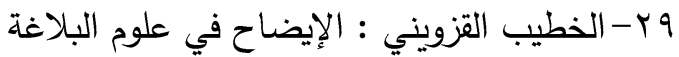



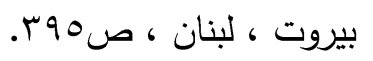



اس- الديوان : صع V.






مr ابن حجة الحموي : خزانة الأدب وغاية الأرب ،

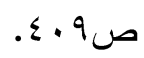

ع ع- الديوان : صریז.

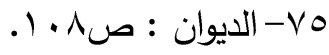











$.1 \leqslant 9 / 1$









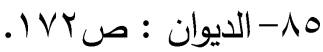



-NV

قائمة المصادروالمراجع



ديوان شمس الدين محم التلمساني ، تحقيق: صلاح الدين الهواري ، دار الكتاب العربي، بيروت ،

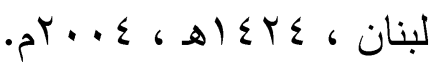

ثانيا : المراجع

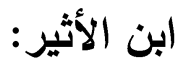

ا - المثل السائر في أدب الكاتب والثاعر ،

تقديموتعليق : أحمدالحوفي. بدويطبانة ،

دارنهضةمصرللطبع والنشر، الطبعةالثانية .

$$
\text { أحمد مطلوب: }
$$

r - معجم مصطلحات النقد العربي القديم

دار الشئون الثقافية العامة ، بغداد ، الطبعة



، ه- ابن أبي الإصبع المصري : تحرير التحبير ،

ص صن.r.

-OV ابن الأثير : المثل السائر في أدب الكتاب والثاعر

، تقديم وتعليق : أحمد الحوفي ، بدوي طبانه ، دار الحير

نهضة مصر للطبع والنشر ، الطبعة الثانية ،

$$
. r 09 / 1
$$

101-ابن رشيق القيرواني : العدة في محاسن الثعر

وآدابه ونقده ، تحقيق: ححمد محي الدين عبد الحميد ،

دار الجيل ، الطبعة الخامسة ، 1 •ـ اهـ ، 19191،

$.1 \vee \leqslant / 1$

9ه- الديوان : صץ؟





ז





07- الديوان : صـ00ب.

7 7- عدنان حقي : المفصل في العروض والقافية وفنون

الشعر ، دار الرشيد ، دمشق ، بيروت، مؤسسة



(

VIT-الخطيب القزويني : الإيضاح في علوم البلاغة ،



^^-ابن الأثير : المثل السائر في أدب الكاتب والثاعر

$$
\text { . } r \wedge 1 / 1 \text { ، }
$$

9 7- عبد الله الطيب المجذوب : المرشد إلى فهم أشعار

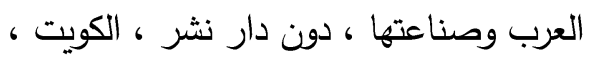

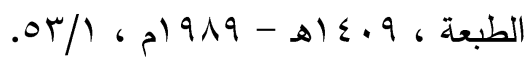







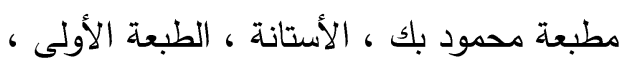




، والبديع ، توثيق يوسف الصميلى المكتبةالعصرية ، صيدا ، بيروت ، 999 (م. صلاح الاين الصفدي:

| ا - جنان الجناس في علم البديع ، مطبعة الجوائب ، قسطنطينية ، الطبعة الأولى ، .8) 199 عبد الرحمن الوجى: - الرجى rا - الإيقاع في الشعر العربي ، دار الحصاد للنشر والتوزيع ، دمشق ، الطبعة الأولى ، 9199 أح. عبد الله الطيب المجذوب: با - المرشد إلى فهم أشعار العرب وصناعتها ، دون دار نشر ، الكوبت ،

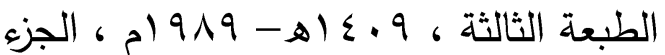
الأول- دار الآثار الإسلامية ، الكويت ،


الثانى - دار الفكر للطباعة والنشر والتوزيع، بيروت ، الطبعة الأولى ، · ل ام ، الجزء



\section{عبده عبد العزيز قلقيلة:}

ع ا - البلاغة الإصلاحية، دار الفكر العربى،


. $999 r$

\section{عدنان حقي:}

0

الثعر ، دار الرشيد ، دمشق • بيروت ، مؤسسة الإيمان ، بيروت ، لبنان ، الطبعة



ابن أبي الإصبع:


نهضة مصر للطباعة والنشر والتوزيع - ن ع- تحرير التحبير فى صناعة الثعر والنثر وبيان إعجاز القرآن ، تحقيق حفنى حمد شرف ، المجلس الأعلى للشئون الإسلامية ، لجنة إحياء التراث الإسلامى جلال الدين السيوطي:

0- جني الجناس ، تحقيق ودراسة وشرح : محمد على رزق الخفاجى ، الدار الفنية للطباعة والنشر ، بيروت ، لبنان ل ابن حجة الحموي: 7- خزانة الأدب وغاية الأرب كشرح عصام شعيتو ، منشورات دار ومكتبة الهلال ، بيروت ـ لبنان ، الطبعة الأولى ، 9AV ام. الخطيب القزويني:

V- الإيضاح في علوم البلاغة والمعانى والبيان والبديع ، دار الكتب العلمية ، بيروت



1- التلخيص في علوم البلاغة ، ضبط وشرح وتحقيق : عبد الرحمن البرقوقى ، دار الفكر العربى ، الطبعة الأولى ، ع. 9 اهـ. ابن رشيق القيرواني: 9- العددة في محاسن الثعر وآدابه ونقده ، تحقيق محم محي الدين عبد الحميد ، دار الجيل ، الطبعة الخامسة ، 1 . عـ اهـ . 9191 السيد أحمد الهاشمي: • 1 - جواهر البلاغة في المعاني والبيان 


$$
\text { مصطفى الصاوي الجويني: }
$$

9 1 - البلاغة العربية تأصيل وتجديد ، منشأة



ثالثًا : المقالات واللدوريات:



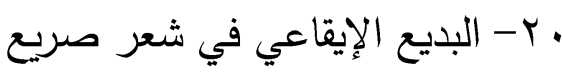





$$
\text { العسكري: }
$$

17 - كتاب الصناعتين "كتابة والثعر" ، مطبعة محمود بك ، الأستانة ، الطبعة





ا IV دار الفكر العربى ، مصر • كحم الهادي الطرابلسي:

11- خصائص الأسلوب في الشوقيات ،



